\title{
Research on High School Students’ Everyday Life in the New Curriculum Reforms Implementation Progress in China
}

\author{
Xiao Yang \\ Teacher Education School, Shanxi Normal University, Linfen, China \\ Email: yangxiao@sxnu.edu.c
}

Received November $11^{\text {th }}, 2013$; revised December $12^{\text {th }}, 2013$; accepted December $19^{\text {th }}, 2013$

\begin{abstract}
Copyright (C) 2013 Xiao Yang. This is an open access article distributed under the Creative Commons Attribution License, which permits unrestricted use, distribution, and reproduction in any medium, provided the original work is properly cited. In accordance of the Creative Commons Attribution License all Copyrights (C) 2013 are reserved for SCIRP and the owner of the intellectual property Xiao Yang. All Copyright (C) 2013 are guarded by law and by SCIRP as a guardian.
\end{abstract}

\begin{abstract}
In this paper, we employ qualitative research to examine the current situation of the implementation process of high school new curriculum reform, and study how to deal with high school students' everyday life in China. The research revealed the contradictions and problems involving the students' living environment, life structure, communication environment and spiritual life. Comparing "eternal ordinary or the moment of fresh" with the goal of curriculum reform and the students' expected life, I found the deep problems about educational ideas, curriculum design, teaching patterns, evaluation criteria and etc. During the process of the reform, I further propose that the students understand everyday life rationally and critically, change the free state of life gradually, improve the structure and pace of life. Only by this can we realize the transformation of the students' life, achieve all-round development following the nature of human-beings, and further deepen and develop the implementation of curriculum.
\end{abstract}

Keywords: New Curriculum Reform; Curriculum Implementation; Everyday Life; High School Students

\section{Introduction}

In order to develop a democratic, prosperous, strong and harmonious socialist modern China, it is necessary to raise the quality of the citizens, and each person must receive holistic and individualized development. The high school new curriculum reform was implemented in mainland China in 2004. The most recent outline for the development of education in China pointing to the need to raise the quality of the citizens and promote all-round development is the means to societal progress. The new curriculum reforms emphasized that creative talent could be cultivated through curriculum reform. In the new curriculum reforms implementation process, the spirit of new curriculum reform should be put into work in high school students' everyday life, which is the most thorough and true. Everyday life serves as the soil in which all students' activities and relationships sprout and grow up. The nature of high school students' holistic and individual development depends on everyday life. Therefore, the study examined the current situation of the implementation process of high school new curriculum, and studied how to deal with high school students' everyday life. How do students live in the implementation process of new curriculum? What are the students' desires and motivations in their everyday life? What is the root cause that determines the generation, development and change of their intentions and motives? Has the spirit of new curriculum been implemented completely to the students' everyday life?

Walking into undifferentiated and habitual everyday life of high school students, the study analyzes contradictions and problems existing in the aspects such as pace of life, life struc- tures, life space, communication environment and spiritual life, which are influenced by the new curriculum reform, then, examines and criticizes them to reveal the deep contradictions of students' life in the reform process of new curriculum. After that, it discovers and denies the barriers that constraint their free and all-round development, then promotes the students' rational and critical understanding of their daily life. Finally, it gradually changes their life comfort and life structure, realizes the transformation of their everyday life, enhances the students' nature of being human, further deepens the effectiveness of new curriculum implementation, and promotes curriculum reform smoothly.

\section{Curriculum Implementation and the Everyday Life}

The curriculum implementation study began with American researchers' systematic reflections on curriculum reform movement of failed "disciplinary structure". The researchers realized that if the curriculum implementation process was not taken seriously, even the most perfect curriculum plan could not make the curriculum reform achieve its desired results. According to the relationship between curriculum plan and curriculum implementation, American curriculum scholars Snyder, Bolin and Zumwalt boiled the orientations of curriculum implementation into fidelity orientation, mutual adaptation orientation and curriculum enactment orientation, and analyzed the characteristics of curriculum implementation process from these five aspects as curriculum, curriculum knowledge, curriculum reform, role of teachers and research methods, etc.

At the beginning of studying curriculum implementation, 
Chinese researchers mostly referred to the ideas of American curriculum scholars to analyze the current situation of Chinese curriculum implementation (Yin \& Li, 2007). With the development and deepening of Chinese curriculum reform, curriculum implementation increasingly highlighted the complexity of itself. Chinese curriculum researchers found that the phenomena of Chinese curriculum could not be explained effectively when referring to curriculum theory from abroad and gradually got out of western discourse authority in curriculum implementation studies. On the macro level, the requirements of ideal curriculum implementation were planned; the tension and conflict between new university entrance examination and high school new curriculum were analyzed; the current situation, difficulties, problems of curriculum implementation were described and explained and the corresponding measures or suggestions to deal with those problems were sought (Zhang \& Xu, 2006; Jin, 2001; Ma, 2002; Zhang, 2007; Liu, 2007; Yu, 2007). On the middle level, the due corresponding strategies of schools were discovered in the curriculum reform process: schools implemented curriculum planning, credit system and elective courses, improved school environment, changed teaching methods and students learning ways, strengthened curriculum leadership, organized teacher training effectively to promote the implementation of national curriculum, local curriculum and school-based curriculum, and then achieved the transformation from the national ideal curriculum to the real curriculum (Cui, 2007; Zhong, 2008; Pan, 2007). On the micro level, the subjectivity of students was respected, and students' psychology was cared for, and most students were found to hold a positive attitude towards new curriculum but felt stressed about it while some, lacking of knowledge of new curriculum, could not adapt to the new curriculum evaluation methods (Dai \& Zhang, 2007). Some researchers, taking reconstructing the world of classroom life as a breakthrough, emphasized that classroom teaching should be connected with life experiences of both teachers and students so as to provide the foundation for the professional world of classroom teaching (Wang, 2006). Chinese education researchers' studies of classroom teaching life only stayed on theoretical criticism, and did not really walk into students' everyday life.

In the 20th century, many philosophers focused on the world of everyday life from different perspectives and put forward the theory of everyday life. In his Crisis of European Science and Transcendental Phenomenology, Husserl pointed that human being's entire worldview was dominated by empirical science, and deviated from the rationalist tradition of concerning about the questions of life, which excluded the questions of human life from scientific world, thus human being lost their meaning and value world (Husserl, 1976). Through the dissection of human being's daily "co-existence”, Heidegger reveals a deep and overall dissimilation in the modern world of everyday life. From the perspective of internal contradictions of daily life, Lefebvre said that simple, free, spontaneous and repetitive as it was, daily life was holographic, which showed the deep inner mechanism of society. To criticize the daily life was to tear the political and economic veil covered on it, liberated the individual subjectivity, and changed the entire social relations (Lefebvre, 2002). Heller noticed that associations existed in the individual, society and daily life: daily life as an individual field of reproduction was irreplaceable and it was the basis of social reproduction, and daily life characterized by repetitive thinking and repetitive practice possessed the property of con- servatism and inertia which often played a negative role in hindering personality development and corrupting the development of creative practice and creative thinking (Lefebvre, 1991).

Examined by the philosophy of the theory of everyday life, daily life__ the basic existing world of high school students, was found to possess characteristics of the following aspects.

First, it is already established. Everyday life always makes identification and acceptance of the established existence as the premise, for example, students can not choose family, birth or gender and they can not select circumstances of life arbitrarily, either. Acknowledgment and acceptance of the established existence not only influence and form individual's lifestyles and everyday interests, but also restrict their behavior ways, thus the individual will set the established circumstances of life as their background (Schutz, 2001); although daily life is not completely unchanged, it more often appears with circulation and repetition of the same or similar model (Heller, 1990). To accept and acknowledge the established world means to agree that it is real and true. The "free" feature of everyday life first requires high school students to adapt to their established life rather than reflect on or criticize it. Having lost the consciousness of reflecting and criticizing for a long time, students are easily inclined to follow the beaten track easily when thinking which also imposes restrictions on the individual to ask the meaning of existence. This established life pattern, always happening and formed in the past but existing at present, first associates with the past from the perspective of time dimension, and correspondingly, the process of daily life generally works with the established pattern, which was the case in the past, and usually such in the present.

Second, it is free. Everyday life is a free, unconscious, habitual activity. Every day high school students get up at six, then, running, reading, having breakfast, attending classes, etc, the activities of which have rooted in the tradition and common sense of school teaching. Daily life guarantees the continuation of school culture in its form of "free" feature, provides students with interpretation of the daily facts, and forms into behavior norms which guide students how to behave correctly. Such norms and tradition have made students accept various routines and existence in school daily life, and they believe that the existing is common, natural and also reasonable and all seems to be self-evident and naturally reasonable (Schutz, 1983).

Third, it is repetitive. In high school students' daily life, today and tomorrow are circular and similar. That is to say, every day in their daily life can be exchanged for another day accordingly. They get up early in the morning, do morning exercises, have breakfast, read in the morning, attend classes, then they have lunch, have a rest, attend classes, do activities, and then have dinner, study by themselves and sleep. In the repetition day after day, the behavior of students or their pace of life are displayed in the same pattern of circulation or repetition. That is to say, students' life habits, daily interests and communication styles are shaped in repetition and circulation, and their ways of dressing and behaving themselves and learning styles are restricted by the background of the established circumstances of life. The mental set, influenced by the long-lasting life pattern and learning style, can hardly stimulate high school students' creative thinking.

Examined by the philosophy of the theory of everyday life, the high school students' daily life includes not only activities that meet the basic conditions of the existence of the individual life and guaranteeing the reproduction of the individual, and 
social relationship activities that are multi-formed inter-individual interactions in the form of language and practice, but also contains daily concept and consciousness that are rooted in those activities. In fact, when we understand the reproduction of the individual not only from the level of the existence of life, but also from the level of the existence of culture, social activities, such as daily life, work, cultural creation function as the ways of achieving the reproduction, get their proper meaning. In short, daily life firstly means an activity that can sustain its life and this also refers to an activity that can survive the individual. Secondly, it involves a variety of activities done by the individual aiming at developing the individual on the basis of living. Thirdly, it means the daily concept and consciousness that are rooted in survival and developmental activities. Among these three activities, the first one is the basic activity of high school students' individual existence, which mainly includes their life structure and pace of life; developmental activity refers to the one that can improve life quality of the individual and can contribute to growth and development of the individual, and it consists of learning activities, interpersonal relationship activities and entertainment activities; daily consciousness and daily concept are things that hidden in the activities of guaranteeing existence of the individual life and promoting the individual development, which refer to the self-recognition and self-evaluation of high school students, cognition of state of their present life, visions of their own future and so on.

\section{Data and Methods}

The survey was conducted on three high schools of different levels in Yuncheng city, Shanxi province central,PRC. The schools are Kangjie Middle School, a provincial key high school, Yuncheng Middle School, a provincial model high school and AnYi Middle School, a township high school. Five classes were randomly selected from grade 1 and grade 2 in the three schools. Six students were randomly selected from each class to be interviewed with their daily lives. 180 students were interviewed on their daily life.

Observation and interview were adopted to learn about their daily life and find out the influencing factors of their daily life. Students' daily life was observed and relevant interviews were conducted on it. Researchers compile a structural interview outline. The following are the main contents: students' daily life, the respondents' memory about when they get up, have the breakfast, go to school, attend class, finish the class and go to bed, helping them establish a comprehensive impression on yesterday; to understand students' views on going to college and objectives of attending high school; to understand students' study activities, such as teaching methods, learning methods, learning content; to understand their relationship with teachers and classmates and their favorite activities and teachers, etc.

Qualitative analysis software QSR Nvivo7 was used to encode and analysis the data. The items of the coding are time table, the purpose of going to high school, opinions on going to college, learning methods, optional courses, hobby, favorite teachers, social practice, relationship with teachers and classmates and self assessment. Differences and common characteristic of students from three schools in these aspects were analyzed according to the related data coding. The results were reached with daily activities as a guide through analyzing ideas and concepts behind the data, reading these data repeatedly, examining the data with law of everyday life at the same time, shuttling back and forth between theory and data. The expected result was achieved through reviewing the data concerning high school students' daily life.

\section{Results and Discussion}

\section{Activities Responsible for Students’ Existence: Pace and Structure of Everyday Life}

The results from analyzed from three aspects: activities responsible for students' existence, activities exciting high school students in daily life and ideas and consciousness hiding in daily life. Three schools have roughly same daily schedule. "Students get up at five Fifty in the morning to, run at six ten and finish the morning exercises at six ten. Then, they have breakfast and do morning reading from six fifty to seven forty. At 7 o 'clock the first class ends, at nine forty the second class ends and at ten o 'clock the class breaking setting up exercise begins. At eleven o 'clock the third classes is over. Lunch begins at 12 o 'clock, then from twelve to fourteen ten lunch break. The first class in the afternoon is at 2:30, the fifth class is at three twenty and the sixth class is at four and twenty. From four and twenty to five is the activity time, the next class begin at five and ten. The dinner began at six, followed by four self-study classes, night training and sleeping (interview with students from Kangjie High School). Main elements in students' daily activities are studied, including eating, sleeping and exercise. As a student said, "every day at school is regular and nothing new. We get up, have breakfast, do morning reading, have classes, have lunch and noon break and attend classes again.” In this structure, study is of primary importance served by eating; sleeping and exercise. We should drink milk, have meat and eggs every day to ensure nutrition for study in high school is very exhaustive (interview with students from Kangjie High School). "In Yuncheng High School we are mandated to attend activities by turning off all the lights in classrooms." "Some of the students have a poor sleep in dormitory, so in order to ensure their learning efficiency they rent a house to live outside the school" (interview with students in Kangjie High School). The pace of life of high school students remains changeless. There are as long as twelve to fourteen hours for study, however less than eight hours for sleeping, one to two hours for exercise and one to two hours for dining. The changeless, repeated and established pace of life in which students sit still for a long time for study, goes against the law of inset activity of cerebral cortex and protective inhibition and deprives their time for sleeping, exercising and relaxing. In the pace of life students feel ordinary and stale.

\section{Activities Exciting High School Students in Everyday Life: Study}

Learning is the bounded duty of a student. The quality of learning activity represents of the quality of students' everyday life. We do a research on high school students' learning activities by studying the learning content, learning method, communicative activities, leisure activities, etc.

\section{Contents of Learning}

Students' study contents $\mathrm{f}$ three schools are the same. Study contents are made up of subjects, mainly including the compulsory courses for grade one and grade two, like Chinese, math, English, music, sports, art, general technology, the in- 
quiry learning. In addition, the students majoring in science of grade two will learn physics, chemistry, biology, and students of arts should learn politics, history and geography. In the new round of curriculum reform, optional courses are included in high school courses and content of courses is designed by module. Students can take courses by modules. In three schools, teaching is conducted according to content of college entrance exam which all the students are required to learn and no optional courses is offered.

\section{Learning Method}

Students in three schools pay much attention to memorization in the learning process, holding that reciting is the basis of the study and the primary goal in cognitive activities, based on which they can improve their ability of understanding, analysis, synthesis, application and evaluation. It seems to students that learning is "reading, studying and reciting" (interview with students of Anyi High School).

In addition to recitation, students in Yuncheng High School and Kangjie High School also pay special attention to understanding. They are aware of the importance of thinking ability, believing that only by learning can they improve the ability of solving problems and improving academic performance. To achieve good performance we need to think, find and understand the relationship between phenomenon and rules. Thinking reflects students' subjectivity and self-consciousness in learning process. Thinking ability helps students solve problems in a strange environment. "Listening to and understanding the lecture is of great importance, for the teacher can explain one question at class but he cannot cover all the questions, so if we can draw inference about other cases from one instance, we can generally understand it. More reviews are necessary to avoid mistakes of the same questions." (Interview with students of Kangjie High School). "In learning Chinese we should think more and do more exercise to expand our thought, for articles on the textbook will not covered in exam. " (Interview with students of Yuncheng High School)

\section{Communication Activities}

There are mainly two types of communication activities concerning students: the first one is communication with teachers, the other is contact among students. The relationship with teachers is a key element in students' study activities. Teachers are important to students, whose knowledge, self-cultivation and personality have great impact on students. Their favorite teachers have the greatest influence on them. The popular teacher is the one who is knowledgeable and humorous, both serious and lovely in class; who has excellent professional knowledge and gets along with students like friends, who can explain knowledge thoroughly by linking theory with practice; who has witty thought and cares for students. As what is popular among students: the first-class teacher reveals us truth, the second- class teacher teaches us methods and the third-grade teacher analyzes the specific examples. In the process of communication what can touch students mostly is teachers' care and understanding of students. "My math teacher has never given me up, which impresses me, for I do not expect such a veteran as him should be so patient. It is impossible even for my mom. Sometimes I cannot finish my homework for lack of time or ability. The teacher will criticize me, but never gives me up. His persistence may not determine my success or failure, but it determines my attitude. It at least changes my negative attitude towards mathematics "(interviews with students of Yuncheng High School). The math teacher's care and help make the student understand the teacher will never give him up, which changes his attitude to math. The highest state of education is: "education is the education of man's soul, rather than the accumulation of reasonable knowledge and cognitions. Education of talents allows them to decide what kind of people they would like to grow and how they earn a living”.

High school students tend to choose congenial classmates as their friends. "I like reading and writing some reaction to articles which I like sharing with my friends. She is very knowledgeable with independent thoughts and we are good friends". (interview with students of Kangjie High School). I get well with my classmates. I stay with them all day. We go back to the dormitory together and study together. I feel happy all day. My classmates often help me with difficulties in study, making it easier for me to study. "(interview with students of Yuncheng High School,) Good relationship with classmates brings high school students warm and comfortable feelings.

\section{Leisure Activities}

Activities that students of the three schools participate are sports meeting organized by students' union, recital contest, singing competition, composition contest, basketball match, tug of war and New Year's day evening party, etc. As a platform for students to improve themselves, these activities are very popular, through which students can understand the society, nature and themselves. "I have participated in the speech contest for many times, I won the second prize in” Wen Yiduo's prayer”. I feel happy for it proves my ability." (interview with students of Kangjie High School). At three schools these activities are linked with national college entrance exam. Take Kangjie High School as an example, "because the school gives each class an enrollment index for national college entrance exam. Students with specialties are included in the evaluation system this year. In each class there must be at least one student with specialties enrolled in college, no matter what kind of specialty, such as director, music, sports, for the philosophy of Kangjie High School is "every student can be successful, every student has a stage”. (interview with students of Kangjie High School).

Social practice is formulaic; as a result, students cannot really enter and understand the society, which attributes that the national college entrance examination does not cover the social practice. "About Social practice, well, the school sends us a form on which we are required to write a summary and get a signature. In social practice, I choose to go to the Forest Supermarket and help push the shopping cart and ask for a signature in the end. I participated only one time, and in the second time it is mostly ignored by the teacher, so I only write a summary and sign for it without doing anything." (interview with students of Yuncheng High School)

\section{The Concept and Consciousness of High School Students in Everyday Life-Internal Motivation}

\section{Who Am I?}

Self-cognition is a starting point for one to self-understanding. For the high school students, there are two aspects to refer to. First, they would choose to use academic records to make self-assessments. But the feedbacks from the interview suggest that the academic records do not promote the students' devel- 
opment but produce psychological pressure. "Because a bad academic record means that we can not do what we like to and think about something irrelevant with NCEE (National College Entrance Examination)." (Interview with the students in Yuncheng Middle School). Second, although students can recognize and understand what they are during the learning process, most of them do not have a real hobby. For those average students, "the NCEE (National College Entrance Examination) gives me much pressure so that I am in fear of getting poor grades which mean the refusal of college. Therefore, I couldn't afford to waste my time”, says a student in Anyi Middle School. For students in qualified schools, they have their own hobbies which can boost their academic records instead of impacting them. "A girl in our class studies very well and she believes she can attend the best university when graduating. However, she just says she wants to sing and like singing very much. Hearing that, the other students think she is so mad because in their opinions, only those who can not bury their heads into study any more would choose to learn singing.” (Interview with students in Kangjie Middle School). For the high school students, every one should have a hobby of his own on which he can spend plenty of time consciously doing study and research work every day. And during the research process, he can acquire good learning literacy for instance, the breadth of thinking, the depth of thinking, mental agility, the transfer of which is beneficial for learning other courses. At the same time, only by developing good hobbies can the students develop their personality very well.

\section{Why Am I Being This?-The Objective of Attending High School}

Students attend high school with an aim for university. Human beings are purposeful and the purpose and subjective initiative distinguish us from other species. It is the purpose that stimulates people to seek their ideal life day after day. The majority of students work hard to attend famous university in their daily life, which is the popular living state of high school students. This living state forces every one to exist for attending universities and regulates how one should spend a day and then he has to spare no effort to work hard for his plan, for his future. The study finds that the high school students live in the past and future instead of the present. Even though some agree that they also should live a fruitful and happy life at present, the life in high school is still regarded as a transition period to arrange their future. "No matter the parents or the teachers, both of them place much emphasis on the NCEE. But on my part, I just take it as a springboard, a means to success. Getting a good exam results and attending famous university doesn't mean that you are a success and have bright prospect ahead. It is just a piece of springboard, a stepping-stone to success." (Interview with students in Yuncheng Middle School). The present time is not the end of high school students. For them, both the past and the present are means, while the future is the end, which suggests they place more expectations for the brighter and happier future instead of caring about the present. If so, it is inevitable that they have to bear the dullness and boredom of present reality.

Students in good high schools have deeper understanding of the goal of attending school. One student considers it as a piece of pathway among the journey of whole life. "A lot of my classmates think they attend high school aiming for famous universities and take it granted that if they make it, they can even change their life and enjoy wonderful life. I don't agree with it totally, because I think our high school life should be not only fruitful but also happy. No matter acquiring knowledge or learning how to be a good man in this period, each of them is very crucial, or we can say a turning point.” (Interview with students in Kangjie Middle School). From what they said, we can find that on one hand, they want to attend university and on the other hand they also emphasis on spending every day feeling satisfied and happy. It indicates they have the learning autonomy, subjectivity, and a better understanding of their own life. In other words, they can hold a right perspective on life, study, activity and NCEE. Moreover, they realize that the goal of attending high school is to pursuit happiness of the whole life which consists of that of every day in reality.

\section{Where Do I Want to Go? -----What's Your Opinion on Attending University?}

All the high school students wish to attend university. Everyone's objective of life should be different. Giving it an accurate definition is the motive of each student in the daily activities. Both the objective and the worry are the basics of important motives of human's thinking and behavior, playing an important guiding role on the individual's development. The objective determines, to a certain degree, the field that the individual will choose to take up in the future, while the worry is beneficial for the individual to make an objective assessment of the possible problems occurred in the self-developing process and as a consequence, it leads him to construct and realize his goals. Only when students recognize what they like can they better set their goals. So it makes sense that those who don't have any interest or hobby don't have appropriate and viable objective for life.

\section{Conclusions and Recommendations}

\section{Conclusions}

\section{The Constant Routine and Momentary}

Freshness-Analysis of High School Students' Daily Life

For the majority of the Chinese students, they expect to change their fate by receiving education. And the school, students and teachers are all very concerned about whether the students can become winners in this NCEE fighting. As a result, the students' daily life are not paid much attention to, and become a means to make variety of extrinsic purposes come true. After further analysis, we can find there are several reasons for the institutionalization of our education. First, there is misunderstanding of our teaching philosophy, that is, we can't make a good differentiation between becoming a grown-up and becoming a useful person. Becoming a grown-up refers to a person who can gain the ability to develop and become a social man after later acquisition. But becoming a useful person means after school cultivation and conscious knowledge transfer, one can acquire a certain skill to live on so that he can be independent and take part in social activities. On the society's part, it needs a useful person who can be regarded as a human resource to promote social development. The aim of school cultivation is not for students' attending university but teaching them to acquire ability of independence so that they can take part in social activities during the socialization process. What's more, this ability refers to not only good academic records but 
also sound development in the physical, psychological and mental aspects. Second, education proceeds to prepare for the grown-up's happy life but neglects students' present needs for progress. Third, the NCEE admittance standard is a bit rigid. Since the NCEE is the guideline of school teaching and the student's academic records are the only reference for university's admission, the students have to pay more attention to their scores. If there is another aspect to consider about, for instance, students' overall development, it will have a great impact on their everyday life. Fourth, the training objectives of school don't serve for country's education objectives which refer to cultivate all-around students. However, in the teaching practices, schools compete with each other openly and secretly in order to enlarge the number of students admitted by the universities, while the students too, strive for attending good universities. It is believed that the education objective of school should lay the foundation stone to realize that of our country. Thus, if the school seeks for the number of students' attending university without further consideration, the education objective of school will deviate from that of our country.

\section{Taking Exams and the NCEE Constantly Reminds Students} of the Routine and Dullness

Taking the NCEE is a necessary phase for students to enhance their literacy so as to find a good job and live a better life. And attending a famous university and finding a decent job is the dream of many students, and can be regarded as a shortterm goal among their whole life. Its existence is inevitably reasonable. But in terms of school, if the school regards students' short-term goals as its own teaching philosophy, the public will suspect its educational objectives. Because making the high school education test-oriented, material-oriented and tool-oriented would distort the will of encouraging students' overall development. It would prompt students to constrict their interest in those contributive to exams, thus weakening their natural curiosity and love for acquisition. As a result, the students' daily life is institutionalized and the high school's educational objectives are mismatched. Education deviates from its essence, while people distort the education and are also manipulated by the distorted education. All of these constantly remind the high school students of routine and dullness in the whole daily life.

\section{Recommendations}

The purpose of criticizing high school students' daily life is not to create a totally new one to take place of it, but to rearrange it. Therefore, I'd like to make the following recommendations on the reform of high school new curriculum.

\section{Reforming High School Students’ Living Structure and Pace in Everyday Life by Reducing Their Study Time, Increasing Their Rest and Leisure Time}

In the primary education phase, the study time of Chinese students is twice of that of American students, but we don't cultivate as many Nobel Prize winners as America because long time study doesn't contribute to students' physical, psychological and personality development. Conversely, if we reduce students' study time and increase their rest and leisure time, the serious learning activities are paused temporarily, the routines and disgusting activities are removed, and the feeling of boredom and dullness is relieved, all of which will liberate the stu- dents physically and mentally so that they can truly feel themselves and develop personality on their own will.

\section{Reforming High School Students' Learning Courses in Everyday Life by Increasing Optional Courses and Putting Optional Courses, Comprehensive Practice Courses into Practice \\ The students' personality development is closely related with} the holistic development, and that neither can exist effectively without the other. Since the high school is a crucial period for students to develop their independence and personality, the school should increase the optional courses and activities to serve for their personality development.

\section{Changing Students' Learning Methods}

Now the students still acquire knowledge in the means of memorizing and reciting. They can not understand the essence of research study, or effectively recognize and solve the problems existed in the reality unless we change the teaching methods and make the classroom become an experimental area for students to explore and construct the ways to solve problems in their own wisdom and ideas. Only in this way can we cultivate the real qualified students who are thoughtful and intelligent.

\section{Changing the School's Education Objectives and Training Objectives}

In terms of education, the school should train students as a person. Because students are, finally, human beings, ordinary ones in the daily life, ones in the developing process, ones with individual consciousness, instead of test-takers, technicians, rational man, laborers, statesman, economists and so on.

\section{Reforming the Current Admission Rules of the University}

When selecting students, apart from the academic records, the university should also take students' development in other aspects into consideration, which will make a big difference on their everyday life.

\section{REFERENCES}

Bonoti, F., \& Metallidou, P. (2010). Children’s judgments and feelings about their own drawings. Psychology, 1, 329-336.

Yin, H. B., \& Li, Z. J., (2007). On teachers' change in curriculum reform. Educational Reseacher, 3. http://dx.doi.org/10.4236/psych.2010.15042

Du, F. F., \& Zhang, M. C. (2006). Reform of college matriculation examinations: Reality and ideal. Journal of Shandong Normal University (Humanities and Social Sciences), 6.

Jin, Y. L. (2001). Curriculum implementation: Situation, questions and expectation. Shandong Educational Research, 11.

Ma, Y. P., \& Tang, L. F. (2002). Investigate new curriculum implementation: Questions and obstacle. Journal of Theory and Practice of Education, 7, 52-55.

Snyder, J., Bolin, F., \& Zumwalt, K. (1992). Curriculum implementation. In W. P. Jakson (Ed.), Handbook of research on curriculum, New York: Macmillan Publishing Company.

Zhang, J. J. (2007). The questions, cause and strategy of the new curriculum. Journal of Tianjin Normal University (Elementary Education Edition), 3.

Liu, L. B. (2007). Analysis and countermeasure research restricting factors of high school new curriculum implementation loaning. Education Research, 7.

Yu, H. J., Shi, J. M., \& Qian, L. X. (2007). The new college entrance examination and high school new curriculum: Hot and confusion. 
People's Education, 11.

Pan, H. J., Li, Z. H., \& Zhou, F. S. (2008). Research on the current state of the elective courses implementation in high school and the solutions. Curriculum, Teaching Material and Method, 3.

Zhong, Q. Q. (2008). Issues and prospects of China's current curriculum reform in the perspective of modern global curriculum renovation. Journal of Ningbo University (Education Edition), 8.

Dai, B. R., \& Zhang, W. (2007). Research on the students' mentality in the course of implementing new curriculum in senior high school. Educational Research, 11 .

Wang, J. (2006). Relationship between education and life. Journal of Huazhong Normal University (Humanities and Social Sciences), 3.

Ministry of Education (2001). Framework for the curriculum reform of basic education (Trial Version). Ministry of Education.
Lefebvre, H. R. (1991). Critique of everyday life. London: Verso.

Lefebvre, H. R. (2002). Critique of everyday life, Vol. П: Foundation of a sociology of everyday life. London: Verso.

Lefebvre, H. R. (2003). Critique of everyday life, Vol. WI, From modernity to modernism (towards a meta-philosophy of daily life). London: Verso.

Lefebvre, H. R. (1994). Everyday life in the modern word. Transaction Publishers, New Brunswick.

Lefebvre, H. R. (1991). The production of space. Oxford: Blackwell Led.

Zhang, H. (1999). The meaning and basic orientation of curriculum implementation. Comparative Education Research, 2.

Husserl, (1976). Ideen zu einen reinen phnomenologie und phnomenologischen Philosophie, Husserlinana Band III/1, Martinus Nijhoff. 